\title{
Fetal Cholelithiasis: A Case Series of Antenatal Sonographic Diagnosis with Review of Literature
}

\author{
Amandeep Singh ${ }^{1}$, Priya Kapahi ${ }^{2}$, Abhiraj Kakkar $^{3}$, Gauravdeep Singh ${ }^{4}$
}

\begin{abstract}
Aim and objective: To evaluate the antenatal diagnosis of fetal cholelithiasis with postnatal outcome.

Background: Fetal cholelithiasis and/or echogenic sludge in the gallbladder is an infrequent ultrasonographic finding seen as echogenic material with or without posterior acoustic shadowing. Fetal cholelithiasis is most commonly seen during the third trimester of pregnancy. In the majority of cases, fetal cholelithiasis/sludge shows spontaneous resolution within a few months of postnatal life. But, it is very important to assure that echogenic foci are present inside the gallbladder lumen to rule out other causes of right upper quadrant echogenicities. Use of 3-dimensional (3D) scan can aid in the diagnosis of fetal cholelithiasis.

Case description: Through this case series, four cases of fetal cholelithiasis were followed up in their postnatal period to evaluate the outcome. Clinical significance: A case of fetal cholelithiasis should be followed for an adequate time frame before thinking on the grounds of surgical management.
\end{abstract}

Conclusion: Unlike adult cholelithiasis, fetal cholelithiasis shows a benign course with self-resolution.

Keywords: Echogenic foci, Fetal cholelithiasis, Fetal gall bladder.

Donald School Journal of Ultrasound in Obstetrics and Gynecology (2021): 10.5005/jp-journals-10009-1815

\section{BACKGROUND}

Fetal cholelithiasis (FC) is generally diagnosed in the third trimester of pregnancy. Most of cases in literature were seen after 28 weeks of pregnancy. ${ }^{1-3}$ It is possible to visualize fetal gallbladder (GB) in the second trimester of pregnancy as an anechoic elliptical structure seen on the right of the intrahepatic umbilical vein. ${ }^{4,5}$ Echogenic material in the fetal GB can have multiple presentations, it can be seen as single echogenic foci or multiple echogenic foci with or without posterior acoustic shadowing or echogenic area (sludge). ${ }^{6-15}$ It is very important to assure that echogenic foci are present inside the GB lumen to rule out other causes of right upper quadrant echogenicities. ${ }^{16}$ These include hepatic calcifications, calcified hepatic masses, or meconium peritonitis, which unlike the benign course of FC, may be associated with a high degree of morbidity and mortality. ${ }^{16-18}$ It gets very difficult to differentiate these conditions from $F C$ especially when the fetal $G B$ is contracted. ${ }^{2,11}$ In addition to normal ultrasonography (USG), a 3-dimensional (3D) scan can also be done to nicely delineate the relation of cholelithiasis with the fetal GB so that other differentials of echogenic foci such as calcified liver masses and meconium-filled bowel can be ruled out.

\section{Case Descriptions}

Case 1

A 29-year-old-woman, gravida 3, para 3, and abortion 0, came for routine antenatal USG at our institute. An old antenatal scan done at some other diagnostic center revealed normal fetus with normal cardiac activity and all growth parameters corresponding to the gestational age ( 25 weeks and 1 day). The USG in our institute was done at 34 weeks and 2 days gestation according to the last menstrual period (LMP). Fetus was in cephalic position

\begin{abstract}
${ }^{1-4}$ Department of Radiodiagnosis and Imaging, SGRD Institute of Medical Sciences and Research, Amritsar, Punjab, India

Corresponding Author: Amandeep Singh, Department of Radiodiagnosis and Imaging, SGRD Institute of Medical Sciences and Research, Amritsar, Punjab, India, Phone: +919872454954, e-mail: dr.amancs@gmail.com

How to cite this article: Singh A, Kapahi P, Kakkar A, et al. Fetal Cholelithiasis: A Case Series of Antenatal Sonographic Diagnosis with Review of Literature. Donald School J Ultrasound Obstet Gynecol 2021;15(4):407-410.
\end{abstract}

Source of support: Nil

Conflict of interest: None

at the time of presentation with fundoanterior placenta. Liquor was adequate and fetal heart rate (FHR) measured 152 beats per minute. The calculated gestational age according to USG was 34 weeks and 3 days. Few small echogenic foci with no posterior acoustic shadowing were observed in the fetal GB. With 5 weeks follow-up, the patient delivered a healthy baby with a weight of 3,200 $\mathrm{g}$ by normal vaginal delivery at our institute. On the 1st day of the postnatal period, abdominal USG of the newborn was done. GB in the newborn was normally distended with echogenic sludge identified in its lumen. The neonate was followed-up at day 25 of life and a repeat USG was done revealing a normally distended GB with clear lumen lacking any GB sludge or echogenic foci.

\section{Case 2}

A 25-year-old-woman, gravida 1, para 1, and abortion 0, came for her first antenatal USG at our institute. Antenatal USG in our institute was done at 31 weeks and 1 day gestation according to the LMP. Fetus was in cephalic position at the time of presentation with

() The Author(s). 2021 Open Access This article is distributed under the terms of the Creative Commons Attribution 4.0 International License (https://creativecommons. org/licenses/by-nc/4.0/), which permits unrestricted use, distribution, and non-commercial reproduction in any medium, provided you give appropriate credit to the original author(s) and the source, provide a link to the Creative Commons license, and indicate if changes were made. The Creative Commons Public Domain Dedication waiver (http://creativecommons.org/publicdomain/zero/1.0/) applies to the data made available in this article, unless otherwise stated. 
anterior placenta with its lower end lying $5 \mathrm{~cm}$ above the internal os. Liquor was adequate with amniotic fluid index (AFI) of 10 and FHR measured 142 beats per minute. The calculated gestational age according to USG was 31 weeks and 2 days. Few small echogenic foci with no posterior acoustic shadowing were observed in the fetal GB. The neonate was followed-up at day 45 of life and an abdominal USG was done revealing a normally distended GB with clear lumen lacking any GB sludge or echogenic foci.

Case 3

A 28-year-old-woman, gravida 2, para 2, and abortion 0, came for routine antenatal USG at our institute. Two antenatal ultrasounds were done in our institute at 16 weeks and 2 days and 37 weeks and 3 days of gestation according to the LMP, respectively. The calculated gestational age according to USG was 16 weeks and 5 days and 37 weeks and 6 days, respectively. Few small echogenic foci with no posterior acoustic shadowing were observed in the fetal $\mathrm{GB}$ in the second scan. The neonate was followed-up at day 40 of life and an abdominal USG was done revealing a normally distended GB with clear lumen lacking any GB sludge or echogenic foci.

\section{Case 4}

A 34-year-old-woman, gravida 2, para 1, and abortion 1, came for routine antenatal USG at our institute. An old anomaly scan (Level II) done at some other diagnostic center at 20 weeks of gestation demonstrated a normal fetus with no gross congenital abnormality. The USG was done at 35 weeks and 3 days gestation according to the LMP. Fetus presented in cephalic presentation with fundoposterior placenta. Liquor was adequate and FHR measured 136 beats per minute. The calculated gestational age according to USG was 36 weeks 1 day. Multiple small nonshadowing echogenic foci were seen in the fetal GB (Fig. 1). In addition to normal USG, a 3D scan was also done to nicely delineate the relationship of cholelithiasis with the fetal GB, so that other differentials of echogenic foci such as calcific liver masses and meconium-filled bowel can be ruled out (Fig. 2). With 3 weeks follow-up, the patient delivered a healthy baby with a weight of $3,000 \mathrm{~g}$ by normal vaginal delivery. On the 1st day of the postnatal period, abdominal USG was done. A normally distended GB showing sludge in its lumen was identified. A follow-up ultrasound was performed at day 20 of life revealing a normally distended GB without any echogenic foci or GB sludge (Fig. 3).

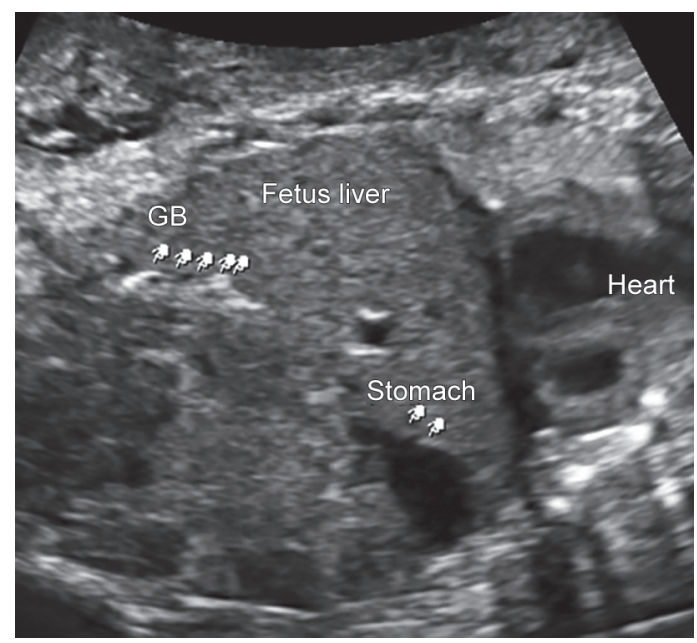

Fig. 1: Multiple echogenic foci without posterior acoustic shadowing noted in gallbladder lumen in third trimester ultrasound scan

\section{Discussion}

The fetal GB develops from the ventral outpouching of the caudal portion of the embryonic foregut at around week 4 of gestation. Hepatocytes start production of bile at around 12 weeks of gestation, which reaches the duodenum at around 13 weeks of gestation. ${ }^{19}$ There occurs a linear relationship in GB size and gestational age from 15-35 weeks of gestation, beyond which sinusoidal contractility pattern initiates. ${ }^{20-24}$

Potter in 1928 identified a few cases of neonatal cholelithiasis and wrote about two poorly documented cases that were diagnosed during postmortem. ${ }^{25}$

First prenatal diagnosis of fetal cholelithiasis was done by Beretsky and Lankin in 1983. Sludge and cholelithiasis of fetal GB are extremely uncommon in fetal life, with a very low incidence of about $0.42 \%$ with a slightly greater male predilection. ${ }^{10,13}$

Many susceptibility factors related to the mother and the fetus have been suggested to be associated with the etiopathogenesis of fetal cholelithiasis. Two main etiopathogenesis theories were put forward by Fanaroff and Brown. Fanaroff suggested that in abruptio placentae, there occurs transplacental passage of hemoglobin,

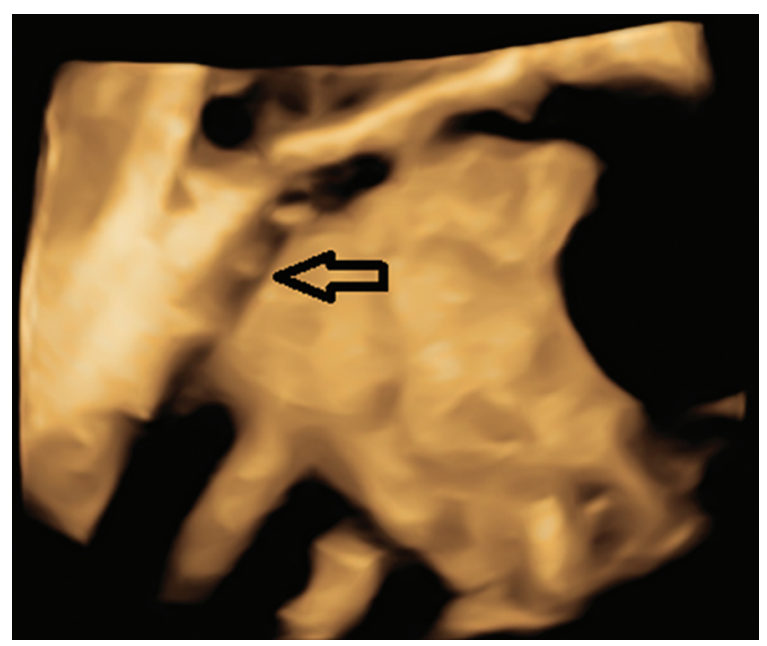

Fig. 2: 3D rendering of fetal gallbladder showing fetal cholelithiasis (arrow)

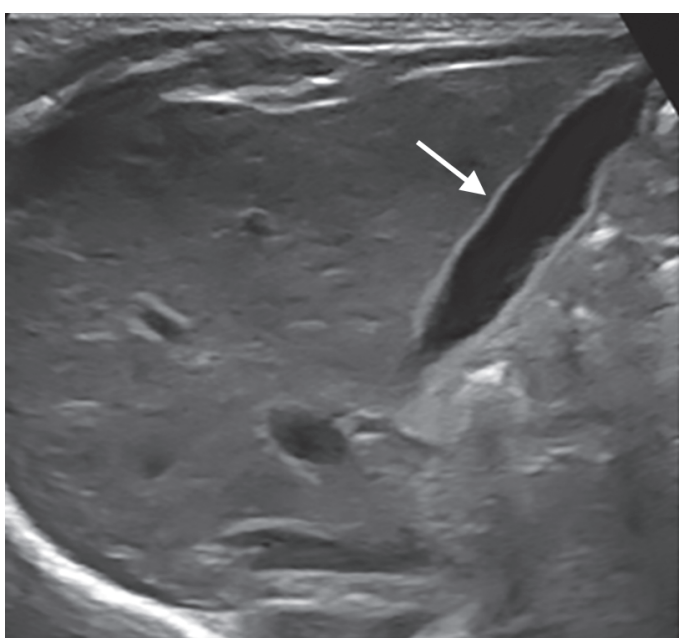

Fig. 3: Follow-up postpartum day 20th scan of newborn revealed Normally distended gallbladder (gb) (arrow) without any echogenic foci or gb sludge 
which gets converted into bilirubin, thereby increasing the indirect bilirubin levels, responsible for FC or GB sludge. ${ }^{26}$ Conversely, Brown suggested that elevated maternal estrogen levels could lead to a decrease in the production of bile salts and increased cholesterol levels, which could lead to the risk of fetal cholelithiasis. ${ }^{26}$ Other theories suggested the role of maternal narcotic consumption, leading to increased enteric transit and GB emptying time could also lead to $\mathrm{FC} .^{26,27}$

An increase in the breakdown of erythrocytes leading to elevated bilirubin levels has been proven to cause cholelithiasis in the postnatal period. A similar scenario might also explain the evolution of FC with hemoglobinopathies of mother and fetus such as Rh incompatibility. $7,8,11,13,15$ Ceftriaxone is well known to precipitate insoluble calcium salts, so the administration of ceftriaxone to the mother during pregnancy and its passage through the placenta to the fetus could also act as an etiological factor of FC. ${ }^{3}$ Other associations with fetal cholelithiasis in the literature include maternal cholelithiasis, ${ }^{11,13}$ maternal diabetes, ${ }^{13}$ prostaglandin use, ${ }^{7}$ prenatal fetal leukemoid reaction, ${ }^{7}$ chromosomal abnormalities, ${ }^{7}$ intrauterine growth restriction, $^{2-4,13}$ amniotic fluid disorders, ${ }^{3,7,10,13,15}$ and various malformation related to heart, gastrointestinal tract (GIT), and genitourinary systems $s^{7,10,13}$ and have been observed in association with FC, but no clear correlation has been proposed. Some authors

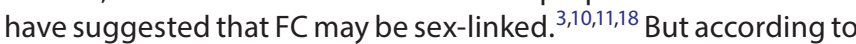
a recent study by Yannick et al., there is no significant association of fetal cholelithiasis and sex of the fetus. ${ }^{6,28}$

In most cases, FC shows a benign course in the postnatal period and unlike adult cholelithiasis, it shows spontaneous resolution. Stringer et al. correlated this spontaneous resolution with altered bile composition and increased biliary outflow leading to the spontaneous dissolution of gallstones. ${ }^{19}$ In the literature, many cases of FC with a complete resolution on postnatal follow-up USG have been documented. ${ }^{2,3,6-13,16-18}$ Most of the cases were treated conservatively and showed complete resolution within 2 months of antenatal period. No medical or surgical therapy was required in most of the cases. This is in concordance to our case series in which all the patients showed resolution of fetal cholelithiasis within 2 months of postnatal life.

\section{Clinical Significance}

Unlike adult cholelithiasis, FC shows a benign course with self-resolution. Therefore, a case of FC should be followed for an adequate time frame in postnatal period before thinking on the grounds of surgical management.

\section{Conclusion}

Fetal cholelithiasis is mainly diagnosed in the third trimester of pregnancy. In most cases, it is a benign and self-limiting disease. Most cases resolve spontaneously in the postnatal period without any complications, so after adequate reassurance of the parents, the patient should be followed up for self-resolution without advising any medical or surgical remedy. But, it is important to differentiate it from other upper quadrant echogenicities since some of them are associated with increased morbidity and mortality.

\section{References}

1. Clarke JP, Roman JD. The outcome of two cases of fetal cholelithiasis. N Z Med J 1994:107(981):270. DOI: 10.1055/s-0042-123840
2. Stringer $M D$, Lim $P$, Cave $M$, et al. Fetal gallstones. J Pediatr Surg 1996;31(11):1589-1591. DOI:10.1016/s0022-3468(96)90189-x

3. Troyano-Luque J, Padilla-Pérez A, Martínez-Wallin I, et al. Short and long term outcomes associated with fetal cholelithiasis: a report of two cases with antenatal diagnosis and postnatal follow-up. Case Rep Obstet Gynecol 2014;2014:1-5. DOI: 10.1155/2014/714271

4. Moon MH, Cho JY, Kim JH, et al. In utero development of the fetal gall bladder in the Korean population. Korean J Radiol 2008;9(1):54-58. DOI:10.3348/kjr.2008.9.1.54

5. Albay S, Malas MA, Koyuncu E, et al. Morphometry of the gallbladder during the fetal period. Surg Radiol Anat 2010;32(4):363-369. DOI:10.1007/s00276-009-0574-z

6. Devonald KJ, Ellwood DA, Colditz PB. The variable appearances of fetal gallstones. J Ultrasound Med 1992;11(11):579-585. DOI: 10.7863/jum.1992.11.11.579

7. Kiserud T, Gjelland $\mathrm{K}$, Bognø $\mathrm{H}$, et al. Echogenic material in the fetal gallbladder and fetal disease. Ultrasound Obstet Gynecol 1997;10(2):103-106.DOI: 10.1046/j.1469-0705.1997.10020103.x

8. Agnifili A, Verzaro R, Carducci G, et al. Fetal cholelithiasis: a prospective study of incidence, predisposing factors, and ultrasonographic and clinical features. Clin Pediatr (Phila) 1999;38(6):371-373. DOI: 10.1177/000992289903800610

9. Müller R, Döhmann S, Kordts U. Fetale Gallenblase und Gallensteine. Ultraschall Med 2000;21(3):142-144. DOI: 10.1055/s-2000-3796

10. Cancho Candela R, Díaz González J, Perandones Fernández C, et al. Material ecogénico en vesícula biliar fetal: diagnóstico prenatal y seguimiento posnatal. An Pediatr (Barc) 2004;61(4):326-329. DOI: $10.1157 / 13066429$

11. Iroh Tam PY, Angelides A. Perinatal detection of gallstones in siblings. Am J Perinatol 2010;27(10):771-774. DOI: 10.1055/s-0030-1254239

12. Abbitt PL, Mcllhenny J. Prenatal detection of gallstones. J Clin Ultrasound 1990;18(3):202-204. DOI: 10.1002/jcu.1870180313

13. Brown DL, Teele RL, Doubilet PM, et al. Echogenic material in the fetal gallbladder: sonographic and clinical observations. Radiology 1992;182:73-76. DOI: 10.1148/radiology.182.1.1727312

14. Lariviere M, Having K, Bullock S. Fetal Cholelithiasis. J Diagn Med Sonography 2006;22:403-406. DOI: 10.1177/8756479306295829

15. Sepulveda W, Stagiannis KD. Echogenic material in the fetal gallbladder in a surviving monochorionic twin. Pediatr Radiol 1996;26(2):129-130. DOI: 10.1007/BF01372091

16. Triunfo $S$, Rosati $P$, Ferrara $P$, et al. Fetal cholelithiasis: a diagnostic update and a literature review. Clin Med Insights Case Rep 2013;6:153-158. DOI: 10.4137/CCRep.S12273

17. Hertzberg BS, Kliewer MA. Fetal gallstones in a contracted gallbladder: potential to simulate hepatic or peritoneal calcification. J Ultrasound Med 1998;17(10):667-670. DOI: 10.7863/jum.1998.17.10.667

18. Holloway S, Edwards H. Antenatal diagnosis of fetal cholelithiasis. Ultrasound 2010;18(3):152-154. DOI: 10.1258/ULT.2010.010017

19. Moore KL: The Developing Human: Clinically Oriented Embryology, 3rd edition. Philadelphia: WB Saunders; 1982. DOI: 10.1002/AJHB.1310050420

20. Hata K, Aoki S, Hata T, et al. Ultrasonographic identification of the human fetal gallbladder in utero. Gynecol Obstet Invest 1987;23(2):79-83. DOI: 10.1159/000298839

21. Goldstein R, Callen P. Ultrasound evaluation of the fetal thorax and abdomen. In: Callen P (Ed). Ultrasonography in Obstetrics and Gynecology, 2nd edition. Philadelphia: WB Saunders; 1988. pp. 207-239.

22. Wei J, Haller J, Rachlin S, et al. Sonographic evaluation of the fetal gallbladder in utero: incidence of visualization and morphology. J Diagn Med Sonography 1993;9(6):291-296. DOI: $10.1177 / 875647939300900602$

23. Tanaka $Y$, Senoh D, Hata T. Is there a human fetal gallbladder contractility during pregnancy?Hum Reprod 2000;15(6):1400-1402. DOI: 10.1093/humrep/15.6.1400

24. Joupilla P, Heikkinen J, Kirkinen P. Contractility of maternal and fetal gallbladder: an ultrasonic study. J Clin Ultrasound 1985;13(7):461-464. DOI: $10.1002 /$ jcu.1870130705 
25. Beretsky I, Lankin DH. Diagnosis of fetal cholelithiasis using real-time high-resolution imaging employing digital detection. J Ultrasound Med 1983;2(8):381-383. DOI:10.7863/jum.1983.2.8.381

26. Fanaroff AA, Martin RJ, Miler MJ. Identification and management of high-risk problems in the neonate. In: Creasy RK, Resnik R (Eds). Maternal-Fetal Medicine, Principles and Practice, 2nd edition, Volume 2. Philadelphia, PA: Saunders; 1989: pp. 1176-1179.
27. Suchet IB, Labatte MF, Dyck CS, et al. Fetal cholelithiasis: a case report and review of the literature. J Clin Ultrasound 1993;21:198-202. DOI:10.1002/jcu.1870210309

28. Hurni Y, Vigo F, von Wattenwyl BL, et al. Fetal Cholelithiasis: Antenatal diagnosis and neonatal follow-up in a case of twin pregnancy - a case report and review of the literature. Ultrasound Int Open 2017;3(1):E8E12. DOI: $10.1055 / \mathrm{s}-0042-123840$. 